\title{
Neuromuscular Block Management in Tracheal Stenosis Surgery; Retrospective Evaluation
}

Etik Kurul Onayı: Bu çalışma için 2020/292 protokol numaralı yerel etik kurul izni alınmış̧ır.

Çıkar Çatışması: Yazarların çıkar çatışması yoktur.

Finansal Destek: Bu çalışma, herhangi bir fon tarafından desteklenmemiștir. Hasta Onamı: Retrospektif çalışmadır.
Ethics Committee Approval: For this study, permission was obtained from the local ethics committee with protocol number 2020/292.

Conflict of Interest: The authors have nothing to disclose.

Funding: This study was not supported by any funding.

Informed Consent: It is a retrospective study.

Cite as: Saylan S, Akdoğan A. Trakeal stenoz cerrahisinde nöromuskuler blok yönetimi; retrospektif değerlendirme. GKDA Derg. 2021;27(1):51-8.

öz

Amaç: Trakeal stenozun cerrahi tedavisinde ister trakeal rezeksiyon-anastomoz gibi uzun işlemler olsun, isterse rijid bronkoskopi ve dilatasyon gibi kısa cerrahi girișimler olsun, hasta konforunu sağlamak ve cerrahiyi kolaylaştırmak için derin nöromuskuler blok gerekebilir. Bu çalışmada trakeal stenozun cerrah tedavisi sırasında sugammadeks kullanılarak yapılan nöromuskuler blok antagonizması incelenmiştir. Calışmamızın amacı, postentübasyon trakeal stenoz ve posttrakeostomi trakeal stenoz olgularında uyguladığımız nöromuskuler blokajın sugammadeks ile antagonizmasını, postoperatif rezidual blok, komplikasyonlar ve postoperatif solunum paternine etkisi yönünden değerlendirmekti.

Yöntem: Kliniğimizde trakeal stenozun cerrahi tedavisi sırasında uyguladığımız anestezi yöntemleri ve nöromuskuler blok yönetimi prosedürlerinin etkinliğini değerlendirmek için hasta dosyaları, anestezi kayıt formları, erken postoperatif takip ve taburculuk süreci retrospektif olarak incelenmiştir. Trakeal stenoz tanısı alan 34 hastanın bir çoğuna farklı zamanlarda birden fazla cerrahi işlem uygulandığı için toplamda 140 girişimsel işlem ve anestezi uygulaması incelenmiştir. Trakeal stenoz cerrahisi geçiren ve nöromuskuler blok antagonizması için sugammadeks kullanılan hastalar çalışmaya dahil edilmiştir.

Bulgular: Hastalarımızın 34'ü postentübasyon-posttrakeostomi trakeal stenoz olarak değerlendirildi. Hastalara kısa cerrahi ișlem olarak rijid bronkoskopi $(n=78)$, balon dilatasyon $(n=35)$ ve stent $(n=5)$ uygulanırken, 22 hastaya trakeal rezeksiyon-anastomoz cerrahisi uygulanmıştır. Kısa ve uzun cerrahi işlemlerde sugammadeks kullanımı sonrası, spontan solunuma başlama zamanının birbirine benzer olduğu görüldü. Sugammadekse bağı herhangi bir komplikasyon tespit edilmedi.

Sonuç: Trakeal stenoz cerrahisinde anestezi derinliği ve kas gücünün monitörizasyonu altında sugammadeks kullanımının nöromuskuler blok antagonizmasında etkin ve güvenilir bir seçim olduğunu düşünmekteyiz.

Anahtar kelimeler: trakeal stenoz, anestezi, nöromuskuler blok, sugammadeks

ABSTRACT

Objective: In the surgical treatment of tracheal stenosis, whether in long procedures such as tracheal resection-anastomosis or in short procedures such as rigid bronchoscopy and dilatation, performing a deep neuromuscular block to provide patient comfort and facilitate the surgery. In this study, neuromuscular block antagonism using sugammadex during the surgical treatment of tracheal stenosis was investigated. The aim of our study was to evaluate the antagonism of the neuromuscular block with sugammadex in cases of postintubation tracheal stenosis and posttracheostomy tracheal stenosis in terms of postoperative residual block, complications and its effect on postoperative respiratory pattern.

Method: In order to evaluate the effectiveness of the anesthesia methods and neuromuscular block management procedures applied during the surgical treatment of tracheal stenosis, patient files, anesthesia record forms, early postoperative follow-up and discharge process were retrospectively reviewed. Since most of the 34 patients diagnosed with tracheal stenosis underwent more than one surgical procedure at different times, a total of 140 interventional procedures and anesthesia applications were examined. Patients who underwent tracheal stenosis surgery and used sugammadex for neuromuscular block antagonism were included in the study.

Results: 34 patients were evaluated as postintubation- posttracheostomy tracheal stenosis. While rigid bronchoscopy $(n=78)$, balloon dilatation $(n=35)$ and stent $(n=5)$ were applied to the patients as short surgical procedures, 22 patients underwent tracheal resection-anastomosis surgery. After the use of sugammadex in short and long surgical procedures, the time to start spontaneous breathing was found to be similar. No complications related to sugammadex were identified.

Conclusion: We argue that the use of sugammadex under the monitoring of anesthesia depth and muscle strength in tracheal stenosis surgery is an effective and reliable choice for neuromuscular block antagonism.

Keywords: tracheal stenosis, anesthesia, neuromuscular blockade, sugammadex
Received/Geliș: 11.10.2020

Accepted/Kabul: 13.01.2021

Published Online/Online yayın: 23.03.2021

Sedat Saylan

Karadeniz Teknik Üniversitesi Tıp Fakültesi Anesteziyoloji ve Reanimasyon Anabilim Dalı

Trabzon - Türkiye sedatsaylan@yahoo.com ORCiD: 0000-0002-4833-9455

A. Akdoğan 0000-0001-7592-3844 Karadeniz Teknik Üniversitesi Tıp Fakültesi Anesteziyoloji ve Reanimasyon Anabilim Dalı Trabzon, Türkiye

(C) Telif hakkı Göğüs Kalp Damar Anestezi ve Yoğun Bakım Derneği'ne aittir. Logos Tıp Yayıncılık tarafindan yayınlanmaktadır. Bu dergide yayınlanan bütün makaleler Creative Commons Atff-Gayri Ticari 4.0 Uluslararası Lisansı ile lisanslanmıştır.

C Copyright The Society of Thoracic Cardio-Vascular Anaesthesia and Intensive Care. This journal published by Logos Medical Publishing. Licenced by Creative Commons Attribution-NonCommercial 4.0 International (CC BY) 


\section{Giriş}

Entübasyon sonrası trakeal stenoz (TS), hava yolunda bir transmural yaralanma alanının sikatrisyel iyileşmesinin neden olduğu bir lezyondur. TS'un en sık nedenleri, trakeal entübasyon ve trakeostomi gibi iyatrojenik travmalardır. Hastalar asemptomatik olabileceği gibi, yaşamı tehdit eden havayolu obstrüksiyonu ile de acil servislere başvurabilirler. Postentübasyon trakeal stenoz (PETS) veya posttrakeostomi trakeal stenoz (PTTS) insidansının \% 6 ile \% 22 olduğu bildirilmiştir ${ }^{[1]}$.

TS tedavisinde genellikle trakeal rezeksiyonanastomoz (TRA) öncelikli olarak tercih edilen yöntemdir. Fakat cerrahiye uygun olmayan ya da bazı özel seçilmiş olgularda bronkoskopik girişimler hayat kurtarıcı olabileceği gibi, cerrahiye kadar geçecek sürede hastaya zaman kazandırıcı ve hatta kür sağlayıcı yöntemler olarakta uygulanabilmektedir ${ }^{[2]}$.

Cerrahi işlem sırasında iyi bir anestezi yöntemi ile uygun ventilasyonu sağlamak ve gaz alışverişini optimal düzeylerde tutmak, işlem başarısı için son derece önemlidir. TS'un cerrahi tedavisinde ister TRA gibi uzun işlemler olsun, isterse rijid bronkoskopi ve dilatasyon gibi kısa cerrahi girişimler olsun, hasta konforunu sağlamak ve cerrahiyi kolaylaştırmak için derin nöromuskuler blok (NMB) gerekebilir. Anestezi pratiğinde steroid yapıdaki nöromuskuler bloker ajanların (NMBA) kullanımı hızlı ve kolay endotrakeal entübasyona (ETE) imkan tanıması ve ventilasyon uygulamasındaki olumlu etkilerinden dolayı artmaktadır. Öte yandan NMB yapıcı ajanların kullanımından kaynaklanan postoperatif rezidüel blok; hipoventilasyon, havayolu obstrüksiyonu, hipoksi ve ölüm gibi komplikasyonlara neden olabilmektedir ${ }^{[3]}$. Rezidual bloğu önlemek için neostigmin gibi antikolinesteraz ilaç kullanımı sekresyon artışı ve bronkospazm başta olmak üzere birçok yan etkilere sebep olabilir.

Sugammadeks steroid yapıdaki NMBA'ın etkisini geri çeviren, gamma-siklodektrin yapıda ve sekiz glukoz molekülü içeren ilk seçici bağlayıcı ajandır ${ }^{[3]}$. Antikolinesterazların neden olduğu yan etki profiline sahip olmayışı NMB'un geri döndürülmesinde kendisine önemli bir avantaj sağlamaktadır ${ }^{[4]}$.

Bu çalışmada TS'un cerrahi tedavisi sırasında sugam- madeks kullanılarak yapılan nöromuskuler blok antagonizması incelenmiştir. Çalışmamızın amacı, PETS veya PTTS olgularında uyguladığımız nöromuskuler blokajın sugammadeks ile antagonizmasını, postoperatif rezidual blok, komplikasyonlar ve postoperatif solunum paternine etkisi yönünden değerlendirmekti.

\section{GEREÇ ve YÖNTEM}

Bu çalışma için 2020/292 protokol numaralı yerel etik kurul izni alınmıştır. Bu çalışma; 2015-2020 yılları arasında, 18 yaş üstü, trakeal stenoz cerrahisi geçiren 34 olguyu kapsamaktadır. Hastaların bir çoğuna farklı zamanlarda birden fazla cerrahi işlem uygulandığı için toplamda 140 girişimsel işlem ve anestezi uygulaması incelenmiştir (Şekil 1).

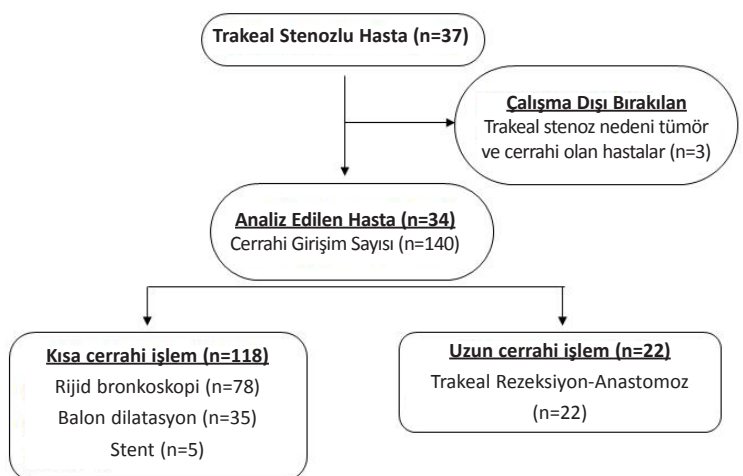

Şekil 1. Çalışma akış şeması.

Kliniğimizde TS'un cerrahi tedavisi sırasında uyguladığımız anestezi yöntemleri ve nöromuskuler blok yönetimi prosedürlerinin etkinliğini değerlendirmek için hasta dosyaları, anestezi kayıt formları, erken postoperatif takip ve taburculuk süreci retrospektif olarak incelenmiştir. TS cerrahisi geçiren, 18 yaşından büyük, steroid yapıda NMBA kullanılan ve NMB antagonizması için sugammadeks tercih edilen hastalar çalışmaya dahil edildi.

Hastaların demografik verileri, American Society of Anesthesiologists (ASA) risk skorları, yoğun bakım ünitesi (ybü) yatış endikasyonu, trakeal stenoz nedeni, ybü’nde kaldığı gün süresi, komorbid hastalıkları, anestezi-cerrahi süresi, spontan ve desteksiz solumaya başlama süresi, trakeostomi şekli, cerrahi tedavi yöntemi, kullanılan ilaçlar ve dozları kayıtlardan 
tarandı. Tüm hastalar postoperatif rezidual blok veya diğer komplikasyonlar yönünden YBÜ'de en az 24 saat süre ile takip edilmektedir.

\section{Anestezi Uygulaması ve Nöromuskuler Blok Yönetimi:}

Hastanemizde trakeal stenozun cerrahi tedavilerinde anestezi protokolü olarak aynı monitörizasyon ve anestezi uygulamaları yapılmaktadır. Bu doğrultuda tüm hastalara; elektrokardiyografi, noninvazif kan basıncı ölçümü, periferik oksijen satürasyonu $\left(\mathrm{SpO}_{2}\right)$, soluk sonu karbondioksit basıncı $\left(\mathrm{EtCO}_{2}\right)$ ve sinir-kas aktivitesi monitörizasyonu yapılmaktadır. TRA cerrahisi geçirecek hastalara ilave olarak; invaziv arteryel basınç, ISI monitörizasyonu, Bispektral İndeks (BIS) ve nöromuskuler blok monitörizasyonu yapılmaktadır. Hedeflenen BIS değeri tüm olgularda 40-60 arasındadır.

Rutin anestezi prosedürü olarak rijid bronkoskopi, balon dilatasyon, trakeal stent yerleştirme gibi kısa cerrahi işlemlerde tüm hastalara \%100 oksijen $\left(\mathrm{O}_{2}\right)$ ile maske ventilasyon uygulanmaktadır, end-tidal $\mathrm{O}_{2}$ yüzdesi \%90'ın üzerine çıkınca cerrahi işleme izin verilmektedir. Anestezi indüksiyonunda intravenöz (iv) midazolam, fentanil, propofol, rokuronyum, lidokain, metilprednisolon, ranitidin kullanılmakta, anestezi idamesi propofol ve remifentanil ile sağlanmaktadır. Kısa süreli cerrahi işlemlerde hastalar aralıklı olarak veya cerrahi ekiple uyumlu şekilde ventile edilmektedir. TRA cerrahisi geçirecek hastalara endotrakeal entübasyon yapılmakta, anestezi idamesi $\% 40 \mathrm{O}_{2}$ - \%60 hava karışımında propofol ve remifentanil infüzyonu ile sağlanmaktadır.

Tüm hastalarda cerrahi girişim tipine bakılmaksızın, hasta konforu ve işlem kolaylığı açısından derin NMB hedeflenmektedir. Sinir kas aktivitesinin monitörizasyonu; akseleromiyografi yöntemi (TOF-Watch ${ }^{\circledR}$ SX, Shering Plough Dublin Ireland) ile addüktör pollisis kasından yapılmaktadır. Tüm hastalarda rokuronyum $0,6 \mathrm{mg} / \mathrm{kg}$ dozunda kullanılmaktadır. TRA geçirecek hastalarda TOF değeri sıfır olduğunda endotrakeal entübasyon yapılmaktadır. Nöromüsküler blok derecesi TOF $\leq 2$ olacak şekilde, gerektiğinde ek rokuronyum $(0,15 \mathrm{mg} / \mathrm{kg})$ uygulanarak sağlanmaktadır. Cerrahi işlem tamamen bittiğinde sugammadeks 4 $\mathrm{mg} / \mathrm{kg}$ dozunda uygulanmaktadır. TOF oranı $\geq 0,9$ olduğunda TOF ölçümü sonlandırılarak hastalar eks- tübe edilmektedir. Spontan solunuma başlama zama$\mathrm{nI}$, cerrahi bitiminden havayolu manevrası ve ventilasyona gerek kalmadan, yardımsız solunumu yeterli hale gelene kadar geçen süre incelenmiştir. Uyanık, oryante ve klinik olarak da kas gücü yeterli olan hastalar yoğun bakım ünitesine alınarak en az 24 saat süre ile takip edilmektedir.

\section{İstatistiksel Analiz}

Veriler, Statistical Package for Social Sciences (SPSS Inc., Chicago, IL) Version 23.0 kullanılarak analiz edildi. Sayısal değişkenlerin normal dağılımı KolmogorovSmirnov testi ile değerlendirildi. Tanımlayıcı istatistikler yapıldı. Sayısal değişkenler ortalama \pm standart sapma (SS) ve medyan (IQR:\% $25-\% 75)$ ve Kategorik değişkenler sayı (n) ve yüzde (\%) olarak verildi.

\section{BULGULAR}

Demografik bulgularımız içinde; kayıtlarına tam olarak ulaşılan 34 hastaya toplamda 140 cerrahi işlemden dolayı genel anestezi uygulandığı tespit edilmiştir. Hastaların tamamında en az bir tane komorbid hastalık mevcuttu. Hastaların özgeçmişlerinde ortalama yoğun bakım ünitesi (YBÜ) yatış günü $23,67 \pm 17,269$ iken, entübasyon süresi $10,40 \pm 6,603$ gündü (Tablo 1).

\section{Tablo 1. Demografik bulgular.}

$\mathrm{n}=37$

\begin{tabular}{lc}
\hline Yaş [yıl, (mean $\pm S D)]$ & $53,11 \pm 16.249$ \\
Cinsiyet [kadın/erkek, n (\%)] & $11 / 26(29,7 / 70,3)$ \\
Vücut Kitle İndeksi $\left(\mathrm{kg} / \mathrm{m}^{2}\right)$ & $26.218 \pm 3.3314$ \\
ASA Risk Skoru $(2 / 3 / 4)$ & $11 / 22 / 4$ \\
Özgeçmişinde YBÜ yatı̧̧ günü & $23.67 \pm 17.269$ \\
YBÜ’ndeki entübasyon süresi (gün) & $10.40 \pm 6.603$ \\
\hline
\end{tabular}

YBÜ: Yoğun Bakım Ünitesi

Trakeal stenoz nedeni olarak; tümör ve cerrahiye bağlı trakeal stenoz dışında (3 hasta, \% 8,1), diğer hastalarımızın tamamında (34 hasta, \%91,9) trakeal stenoz nedeni PETS veya PTTS olarak değerlendirildi. Hastaların ybü yatış endikasyonu ve eşlik eden komorbid hastalıklar Tablo 2'de verilmiştir. İncelenen hastaların üçüne perkutan, onuna cerrahi trakeostomi olmak üzere toplam 13 hastaya trakeostomi açılmıştır. Trakeostomi açılan hastaların onbirinde trakeal stenoz gelişmiştir. 
Tablo 2. YBÜ yatş̧ nedeni, trakeal stenoz nedeni ve komorbid hastalıklar ( $\mathrm{n}=\mathbf{3 7}$ ).

\begin{tabular}{|c|c|c|c|c|c|}
\hline YBÜ Yatış Nedeni & n (\%) & Komorbid Hastalıklar & n (\%) & Trakeal Stenoz & n (\%) \\
\hline KPR Sonrası & $9(24,3)$ & Hipertansiyon & $22(59,5)$ & Entübasyon & $23(62,2)$ \\
\hline Travma & $7(18,9)$ & Koroner arter hastalığı & $11(29,7)$ & Trakeotomi & $11(29,7)$ \\
\hline Ateşli silah yaralanması & $2(5,4)$ & Diabetus mellitus & $11(29,7)$ & Tümör & $2(5,4)$ \\
\hline Pnömoni & $5(13,5)$ & Kalp yetmezliği & $9(24,3)$ & Cerrahi & $1(2,7)$ \\
\hline Malignite & $3(8,1)$ & Tiroid fonksiyon bozukluğu & $3(8,1)$ & & \\
\hline SVO & $4(10,8)$ & Aritmi & $3(8,1)$ & & \\
\hline KKY & $1(2,7)$ & $\mathrm{KOAH}$ & $3(8,1)$ & & \\
\hline Postoperatif takip & $4(10,8)$ & Kronik böbrek yetmezliği & $1(2,7)$ & & \\
\hline İntoksikasyon & $2(5,4)$ & & & & \\
\hline
\end{tabular}

KPR: Kardiyopulmoner Resüsitasyon, SVO: Serebrovasküler Olay, KKY: Konjestif Kalp Yetmezliği, KOAH: Kronik Obstrüktif Akciğer Hastalığı

Tablo 3. Anestezi ve operasyon süresi.

Kısa cerrahi işlemler (rijid bronkoskopi, balon dilatasyon, stent yerleştirilmesi, $n=118$ )

Anestezi süresi (dk)

$27.33 \pm 8.23$

Operasyon süresi (dk)

$21.19 \pm 6.82$

Uzun cerrahi işlemler (trakeal rezeksiyon-anastomoz, $\mathrm{n}=\mathbf{2 2}$ )

Anestezi süresi (dk)

Operasyon süresi (dk)

$152,05 \pm 18.21$

$133.79 \pm 20.33$

Tablo 4. Ek Rokuronyum dozu ve sugammadeks sonrası spontan solunuma başlama süresi.

Kısa cerrahi işlemler (rijid bronkoskopi, balon dilatasyon, stent yerleştirilmesi, $n=118$ )

Ek rokuronyum dozu (mg)

Cerrahi bitiminden spontan solunum başlama zamanı (dk)

$13.04 \pm 4.70$

Cerrahi bitiminden yardımsız olarak spontan solunumu sürdürebilme zamanı (dk)

$4.91 \pm 2.39$

$7.29 \pm 1.62$

Uzun cerrahi işlemler (trakeal rezeksiyon-anastomoz, $\mathrm{n}=\mathbf{2 2}$ )

Ek rokuronyum dozu (mg)

$46.81 \pm 13.93$

Cerrahi sonrası spontan solunum başlama zamanı ( $\mathrm{dk}$ )

Cerrahi bitiminden yardımsız olarak spontan solunumu sürdürebilme zamanı (dk)

$5.22 \pm 2.09$

$10.63 \pm 1.94$

Cerrahi ve anestezi uygulaması olarak; hastalara rijid bronkoskopi $(n=78)$, balon dilatasyon $(n=35)$, stent $(n=5)$ ve trakeal rezeksiyon-anastomoz $(n=22)$ uygulanmıştır. Hastalara ait anestezi ve cerrahi süreleri, ek rokuronyum dozları, spontan solunuma başlama ve spontan solunumu herhangi bir müdahale bulunmadan, yardımsız sürdürmeye başlama süreleri Tablo 3 ve Tablo 4' de verilmiştir. Cerrahi işlem uygulamalarında anestezi yöntemi olarak intravenöz genel anestezi uygulanmıştır. NMB için tüm hastalara rokuronyum $0,6 \mathrm{mg} / \mathrm{kg}$ dozunda uygulanmıştır. Nöromüsküler blok monitörizasyonu yapılan hastalarda TOF $\leq 2$ olacak şekilde, gerektiğinde ek rokuronyum $(0,15$ $\mathrm{mg} / \mathrm{kg}$ ) uygulanmıştır. NMB antagonizması için $4 \mathrm{mg} /$ kg dozunda sugammadeks kullanılmıştır. Ek doz sugammadeks uygulamasına ihtiyaç duyulmamıştır.

Postoperatif takip ve komplikasyonlar; işlem sonrası tüm hastalar özellikle postoperatif rezidual blok ve solunumsal komplikasyonlar yönünden yakın takip ve tedavi amaçlı en az 24 saat süre ile ybü'ne alınmıştır. Erken postoperatif dönemde solunum yetmezliği, dispne gibi komplikasyonlar görülmemiştir. Bir hastamızda ekstübasyon sonrası bronkospazm gelişmiştir.

\section{TARTIŞMA}

TS'un en yaygın nedenleri entübasyon ve trakeostomiden kaynaklanan iyatrojenik travmalardır [5]. Literatür bilgisi ile uyumlu olarak bizim hastalarımı- 
zın \%91,9'unda TS nedeni entübasyon ve uzamış entübasyona bağlı trakeostomi açılması olarak bulundu. TS'un cerrahi tedavisinde uygulanan rijid bronkoskopi, balon dilatasyon, stent yerleştirilmesi gibi işlemler sıklıkla uygulanmış ve başarılı sonuçlar alınmıştır ${ }^{[6]}$. Bu tür kısa süreli girişimsel işlemler yüksek başarı ve düşük komplikasyon oranına sahip olsa da, işlemden bir müddet sonra TS tekrarlayabilir ve TRA tedavisi gerekebilir. Bizim hastalarımıza tekrarlayan minimal girişimsel işlemler uygulanmış, fakat 22 hastaya TRA cerrahisi yapılmak zorunda kalınmıştır.

$\mathrm{Bu}$ hastalara uygulanan cerrahi tedaviler ister kısa süreli isterse uzun süreli olsun, güvenli ve kontrollü havayolu sağlanması bu olguların yönetiminde son derece önemlidir. TS'lu bir olguda tüm alternatif, acil havayolu müdahale ekipmanları hazır bulundurulmalıdır. Çünkü anestezi indüksiyonu sırasında bile hava yolu obstrüksiyonu oluşabilir. Anestezi indüksiyonunda ve trakeal entübasyon öncesi preoksijenasyon, vücuttaki oksijen depolarını artırmak ve böylece apne sırasında arteriyel hemoglobin desatürasyonunun başlamasını geciktirmek için uygulanan, yaygın olarak kabul gören bir manevradır. Preoksijenasyonunda \% 90'lık bir soluk sonu $\mathrm{O}_{2}$ konsantrasyonunun maksimum düzeyde faydalı olabileceği belirtilmiştir [7]. TS'lu olgularda ventilasyon ve entübasyon ile ilgili zorluklar çok daha fazla görülebilir ve preoksijenasyon bu tür olgularda daha da önem kazanır. Bizde kendi hastalarımızda soluk sonu $\mathrm{O}_{2}$ konsantrasyonu \%90’a ulaşıncaya kadar preoksijenizasyon uygulamaktayız.

Aynı zamanda uygulanacak anestezi yöntemi seçilirken hızlı ve yeterli anestezi düzeyini oluşturacak, kısa etkili ve hızlı derlenme sağlayacak anestezik ajanların seçimi ön planda olmalıdır. Propofol, remifentanil ve rokuronyum bu amaçla sık kullanılan ilaçlar arasındadır. Bu tür işlemlerde yeterli anestezi derinliği sağlamanın yanısıra hızlı derlenme için TiVA genellikle ilk seçenektir ${ }^{[8]}$. Biz de kendi kliniğimizde rijid bronkoskopi ve trakeal stenoz cerrahisinde anestezik, analjezik ve NMBA olarak bu ilaçları kullanmaktayız. Ayrıca anestezi derinliğinin takibinde Bis monitörizasyonu kullanılması yüzeyel anestezi riskini ortadan kaldırdığı gibi derin anestezinin yol açacağı olumsuzluklarıda ortadan kaldırır. TRA hastalarında da anestezi derinliği Bis değeri 40-60 arasında olacak şekilde TiVA titrasyonu ile sağlanmaktadır.
Kas gevşeticiler (NMBA), kas tonusunu azaltarak endotrakeal entübasyonu ve mekanik ventilasyonu kolaylaştırır. Bu sayede cerrah için çalışma koşullarını optimize ederek genel anesteziye yardımcı olur ${ }^{[9]}$.

Larinks kasları NMBA'a diğer kaslardan daha dirençli olduğu için rijid laringoskopi ve bronkoskopide derin nöromuskuler blok ile yeterli kas gevşemesi sağlanmalıdır. Dahası, beklenmedik intraoperatif hasta hareketleri ve laringeal yanıtlar mekanik yaralanmalara neden olabilir, kardiyovasküler sistem instabilitesini ve solunum yetmezliğini tetikleyebilir ${ }^{[10]}$. Bu nedenle cerrahi işlem sırasında açık, kontrollü, güvenilir laringoskopik ve bronkoskopik koşulların elde edilmesi ve derin NMB'un cerrahinin sonuna kadar sürdürülmesi arzu edilir.

Rokuronyumun hızlı etki başlangıcına sahip olması ve etkisinin sugammadeks ile hızlı geri döndürülmesi, süksinilkoline uygun bir alternatif olarak kullanılmasına olanak sağlamaktadır ${ }^{[11,12,17]}$.

Genel anestezi uygulamalarında NMBA kullanılması hastaların hızlı derlenmesini olumsuz etkileyebilir ve ciddi postoperatif komplikasyonlara neden olabilirler. Bu komplikasyonlardan en önemlisi postoperatif rezidual bloktur ${ }^{[13,14]}$. O yüzden derlenme öncesi NMBA'ın etkisinin tamamen geri döndürülmesi gerekir. Sugammadeks kullanımı ile derin nöromüsküler blokajdan bile hızlı geri dönüş mümkündür ${ }^{[4]}$. Sugammadeks $4 \mathrm{mg} / \mathrm{kg}$ dozunda rokuronyuma bağlı derin kas gevşemesini birkaç dakika içerisinde tersine çevirir ${ }^{[8]}$.

Woo ve ark.'nın ${ }^{[15]} .118$ hasta üzerinde yaptığı randomize çalışmada TOF oranının 0.9'a ulaşması için geçen ortalama sürenin sugammadeks grubunda ortalama 1.8 dakika, neostigmin grubunda ise 14.8 dakika olduğunu tespit etmişlerdir. Sugammadeksin hastalar tarafından iyi tolere edildiğini ve herhangi bir postoperatif rezidual blok gelişmediğini belirtmişlerdir.

Hızlı ve tam derlenmenin arzu edildiği olgularda nöromuskuler monitörizasyonun yapılması ve indüksiyon sonrası ilave NMBA gereksiniminin buna göre yapılması son derece önemlidir. Ayrıca NMB antagonizması sonrası kas gücünü değerlendirme, ekstübasyon zamanını belirleme ve hasta takibi açısından nöromuskuler monitörizasyon anestezistlere oldukça 
yardımcı olur.

Choi ve ark. ${ }^{[16]}$. kısa cerrahi prosedür olan laringeal mikrocerrahide rokuronyumu $0.45 \mathrm{mg} / \mathrm{kg}$ ve 0.90 $\mathrm{mg} / \mathrm{kg}$ dozunda kullanmalarına rağmen, derin nöromüsküler bloğun geri çevrilmesinde $4 \mathrm{mg} / \mathrm{kg}$ sugammadeksin neostigmine göre daha etkili olduğunu tespit etmişlerdir. Araştırmacılar çalışmalarında laringeal mikrocerrahinin kısa bir işlem olduğunu belirterek NMBA seviyesinin titrasyonu için yeterli zaman olmadığını vurgulamışlardır. Bizim çalışmamızda kısa cerrahi müdahalelerde NMBA etkinliğinin takibinde TOF monitörizasyonu yapılmazken, uzun cerrahi girişimlerin hepsinde TOF monitörizasyonu yapılmıştır. Toplam 118 kısa cerrahi girişiminde, $23(\% 19,4)$ hastaya ek rokuronyum dozu uygulanmışken, uzun cerrahi girişimlerin ( $n=22$ hasta) tamamında ek rokuronyum dozu uygulanmıştır.

Köksal ve ark.'nın ${ }^{[17]}$ kısa bir işlem olan elektrokonvülzif tedavide (EKT) rokuronyum-sugammadeks ve süksinilkolinin derlenme üzerine etkilerini karşılaştırdıkları çalışmalarında nöromüsküler bloktan ve anesteziden derlenmenin rokuronyum-sugammadeks kombinasyonu kullanılan hastalarda süksinilkoline göre daha kısa sürede gerçekleştiğini belirtmişlerdir. EKT olgularında rokuronyumun $0.6 \mathrm{mg} / \mathrm{kg}$ ve sugammadeksin $4 \mathrm{mg} / \mathrm{kg}$ dozlarının yeterli olduğunu ifade etmişlerdir. Araştırmacılar sugammadeks sonrası spontan solunumun başlama süresini 5-7 dakika arasında olduğunu belirtmişlerdir. Bizim hastalarımızda kısa cerrahi girişimlerde benzer süreler söz konusuyken, uzun girişimlerde spontan solunum başlama sürelerinde artış olduğu tespit edilmiştir. Bu durumun uzun cerrahi girişimlerde anestezi süresinin ve kullanılan anestezik-analjezik ilaç dozlarının çok daha fazla olmasının bir sonucu olduğunu düşünmekteyiz.

Önemli ve ark.[18] trakeal stenozlu hastalarda yaptıkları iki olgu sunumunda hızlı anestezi indüksiyonu için $1 \mathrm{mg} / \mathrm{kg}$ dozda rokuronyum kullanmışlar, işlem sonrası 3-4 mg/kg dozunda sugammadeks kullanarak iyi bir derlenme sağladıklarını belirtmişlerdir. Bizim vakalarımızın tamamında rokuronyum $0,6 \mathrm{mg} / \mathrm{kg}$ dozunda kullanılmış ve $N^{\prime} B^{\prime} ı$ sonlandırmak için sugammadeks $4 \mathrm{mg} / \mathrm{kg}$ dozunda uygulanmıştır. Kısa cerrahi girişimlerde hastanın solunum paterni, hemodinamik ve klinik durumuna göre hastalar derlenme odasına alınmıştır. Uzun cerrahi girişimlerde sugam- madeks uygulaması sonrası TOF oranı $\geq 0,9$ olduğunda hastalar ekstübe edilmiştir. Hiçbir hastada ek sugammadeks ihtiyacı olmamıştır.

NMBA'ların kullanıldığı genel anestezi uygulamalarından sonra postoperatif rezidual blok (PORB) hala en tehlikeli komplikasyondur. Yakın tarihli yapılan bir çalışmada non-depolarizan nöromüsküler bloker kullanımından sonra hastaların \% 26.7'sinde PORB olduğunu göstermiştir ${ }^{[19]}$. Choi ve ark.'nın ${ }^{[16]}$ laringeal mikro-cerrahi olgularında yaptıkları çalışmada hiçbir hastalarında PORB gelişmediğini ifade etmişlerdir. Bunun nedeni olarak da hastaların tümünde TOF 0,9'a ulaşana kadar nöromüsküler monitörizasyona devam etmeleri ve sonrasında ameliyathanede trakeal ekstübasyonu gerçekleştirmelerine bağlamışlardır. Bizim hastalarımızın hiç birinde PORB oluşmamıştır. Bu duruma hastaların tamamında sugammadeks kullanılması, postoperatif hemodinamik stabilite ve normal kas gücü sağlanana kadar ameliyathanede derlenme ünitesinde takip edilmesi, sonrasında da 24 saat süreyle YBÜ'nde edilmesinin neden olduğunu düşünmekteyiz.

Sugammadeksin allerjik reaksiyon, bradikardi, arit$\mathrm{mi}$, hipotansiyon, bronkospazm, PORB gibi yan etkileri olabilir ${ }^{[20]}$. Bizim olgularımız içinde sugammadeks sonrası sadece bir hastada bronkospazm gelişmiştir. Bu hastada komorbid hastalık olarak KOAH mevcuttu. Bronkospazmın sugammadeksten mi yoksa mevcut ek hastalıktan mı kaynaklandığını tespit edemedik.

Çalışmamızın bazı limitasyonları vardır; trakeal stenozun cerrahi tedavisi genelde acil cerrahi müdahaleler olup, hastaları standartize etmek oldukça zordur. Bir diğeri kendi kliniğimizde kullandığımız rutin sugammadeks dozları retrospektif olarak incelenmiş, sugammadeksin farklı dozlarda ki (8-16 mg/kg gibi) etkisi incelenmemiştir. Ayrıca farklı dozlarda sugammadeks sonrası oluşan TOF değerleri kaydedilmemiştir. Rutin pratiğimizde sık kullandığımız neostigminin bu tür cerrahi girişimlerdeki etkisi araştırılabilir. Ayrıca hastalarımızın tamamını erken postoperatif dönemde YBÜ' de takip etmemiz olası komplikasyonları önlemede etkin rol oynamış olabilir. Postoperatif servise alınan hastalarda özellikle PORB araştırılabilir.

Özellikle PETS, son yıllarda yoğun bakım ünitelerinin 
ve endotrakeal entübasyon (ETE) gerektiren endikasyonların artışı nedeniyle sık görülen bir komplikasyon olmuştur. Bu durum ETE sonrası kaf basıncı ölçümlerini, kaf dinlendirme periyodlarını ve personel eğitimini daha da önemli kılmaktadır. Bu olgularda steroid yapıdaki NMBA'ların tercih edilmesi sugammadeks kullanılmasına imkan verecektir. Sugammadeks, herhangi bir steroid yapıdaki NMBA'ın nöromüsküler blok derinliğini hızlı ve tahmin edilebilir şekilde tersine çevirebilir. Özellikle asetilkolinesteraz inhibitörleri ile karşılaştırıldığında rezidüel nöromüsküler blok insidansını azaltır, ancak bu konuda daha büyük ve kapsamlı sonuçlar henüz belirlenmemiştir. Sugammadeksin kullanımına bağlı güvenlik endişeleri başlıca aşırı duyarlılık reaksiyonlarına ve kardiyak komplikasyonlara bağlı olsa da, bu alanda daha fazla araştırmaya intiyaç vardır.

Bu çalışmanın sonucunda sugammadeksin postoperatif rezidual blok oluşmasını engellediği ve solunum fonksiyonları açııından iyi bir derleme sağladığı görülmüştür. Sonuç olarak TS cerrahisinde anestezi derinliği ve kas gücünün monitörizasyonu altında sugammadeks kullanımının NMB antagonizmasında etkin ve güvenilir bir seçim olduğunu düşünmekteyiz.

\section{KAYNAKLAR}

1. Storm B, Dybwik K, Nielsen EW. Late complications after percutaneous tracheostomy and oral intubation: evaluation of 1,628 procedures. Laryngoscope 2016;126:1077-82. https://doi.org/10.1002/lary.25766

2. Shin B, Kim K, Jeong BH, Eom JS, Song WJ, Koo H, et al. Clinical significance of differentiating post-intubation and post-tracheostomy tracheal stenosis. Respirology. 2017;22(3):513-20. https://doi.org/10.1111/resp.12925

3. Tayfun ET. Sugammadeks. Kocatepe Tip Dergisi, 2015;16(4):273-8. https://doi.org/10.18229/ktd.14539

4. Fuchs-Buder T, Meistelman C, Raft J. Sugammadex: clinical development and practical use. Korean Journal of Anesthesiology. 2013;65:495-500. https://doi.org/10.4097/kjae.2013.65.6.495

5. Lorenz RR. Adult laryngotracheal stenosis: etiology and surgical management. Curr Opin Otolaryngol Head Neck Surg. 2003;11:467-72. https://doi.org/10.1097/00020840-200312000-00011

6. Rahman NA, Fruchter O, Shitrit D, Fox BD, Kramer mR. Flexible bronchoscopic management of benign trache- al stenosis: long term follow-up of 115 patients. J Cardiothorac Surg. 2010;5:2. https://doi.org/10.1186/1749-8090-5-2

7. Nimmagadda U, Salem MR, Crystal GJ. Preoxygenation: Physiologic basis, benefits, and potential risks. Anesth Analg. 2017;124(2):507-17. https://doi.org/10.1213/ANE.0000000000001589

8. Dincq AS, Gourdin M, Collard E, Ocak S, D'Odemont JP, Dahlqvist $C$, et al. Anesthesia for adult rigid bronchoscopy. Acta Anaesthesiol Belg. 2014;65:95-103. PMID: 25470890.

9. Bruintjes $M H$, van Helden EV, Braat $A E$, Dahan $A$, Scheffer GJ, van Laarhoven CJ, et al. Deep neuromuscular block to optimize surgical space conditions during laparoscopic surgery: a systematic review and metaanalysis. Br J Anaesth. 2017;1;118(6):834-42. https://doi.org/10.1093/bja/aex116

10. Hagberg CA. Benumof and Hagberg's Airway Management, 3rd Edn. Philadelphia: Saunders, 2013;794-802.

11. Turkkal DC, Gokmen N, Yildiz A, Iyilikci L, Gokel E, Sagduyu K, et al. A cross-over, post-electro-convulsive therapy comparison of clinical recovery from rocuronium versus succinylcholine. J Clin Anesth. 2008;20:58993. https://doi.org/10.1016/j.jclinane.2008.06.006

12. Mirzakhani H, Welch CA, Eikermann M, Nozari A. Neuromuscular blocking agents for electrocon-vulsive therapy: a systematic review. Acta Anaesthesiol Scand. 2012;56:3-16. https://doi.org/10.1111/j.1399-6576.2011.02520.x

13. Murphy GS, Szokol JW, Marymont JH, Greenberg SB, Avram MJ, Vender JS. Residual neuromuscular blockade and critical respiratory events in the postanesthesia care unit. Anesth Analg. 2008;107:130-7. https://doi.org/10.1213/ane.0b013e31816d1268

14. Brull SJ, Murphy GS. Residual neuromuscular block: lessons unlearned. Part II: methods to reduce the risk of residual weakness. Anesth Analg. 2010;111:129-40. https://doi.org/10.1213/ANE.0b013e3181da8312

15. Woo T, Kim KS, Shim YH, Kim MK, Yoon SM, Lim YJ, et al. Sugammadex versus neostigmine reversal of moderate rocuronium induced neuromuscular blockade in Korean patients. Korean J Anesthesiol. 2013; 65:501-7. https://doi.org/10.4097/kjae.2013.65.6.501

16 Choi ES, Oh AY, Koo BW, Hwang JW, Han JW, Seo KS, et al. Comparison of reversal with neostigmine of lowdose rocuronium vs. reversal with sugammadex of high-dose rocuronium for a short procedure. Anaesthesia 2017;72:1185-90. https://doi.org/10.1111/anae.13894

17- Köksal E, Üstün YB, Kaya C, Şahin AR, Şahinoğlu AH. Comparing the effects of rocuronium-sugammadex 
and succinylcholine on recovery during electroconvulsive therapy. Anatolian Journal of Psychiatry 2015; 16:198-204.

https://doi.org/10.5455/apd.170334

18. Önemli CS, Çatal DA. Trakeal stenozun rijit bronkoskop ve balon dilatasyonla tedavisinde total intravenöz anestezi kullanımı: Dört olgunun sunumu. GKDA Derg. 20105;21(4):174-9.

https://doi.org/10.5222/GKDAD.2015.174

19. Errando CL, Garutti I, Mazzinari G, Diaz-Cambronero O,
Bebawy JF; Grupo Espanol de Estudio del Bloqueo Neuromuscular. Residual neuromuscular blockade in the postanesthesia care unit. Observational crosssectional study of a multicenter cohort. Minerva Anestesiologica 2016; 82:1267-77. PMID: 27232277.

20. Honing Ghm, Martini $\mathrm{CH}$, Bom A, van Velzen $M$, Niesters $M$, Aarts $L$, et al. Safety of sugammadex for reversal of neuromuscular block. Expert Opin Drug Saf. 2019;18(10):883-91.

https://doi.org/10.1080/14740338.2019.1649393 